\section{EDITORIAL}

For reprint orders, please contact: reprints@futuremedicine.com

\section{Do patient psychological factors influence postoperative pain?}

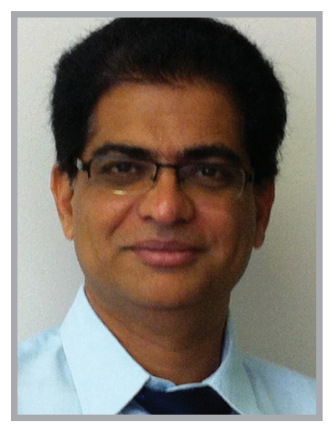

“...only physiological disorders and comorbidities are aggressively managed in the preoperative period. However, it is possible, as well as desirable, to proactively manage the preoperative psychological abnormalities, as a part of the preparation of a surgical patient.”

\title{
Seetharaman Hariharan*
}

First draft submitted: 23 July 2016; Accepted for publication: 16 August 2016; Published online: 31 August 2016

It has been well established that chronic pain syndromes are invariably associated with patient psychological factors such as anxiety and depression states [1]. However, can the psychological make-up of a patient exert any influence in the acute pain experience including postsurgical pain? Is it fair to even consider psychological factors when a patient is suffering the insult and trauma of surgery? Will this lead to the danger of underestimation of pain and provision of oligoanalgesia?

Although these may not be easy questions to obtain answers directly, it may be worthwhile to discuss the wide individual variations in the personal experience of the intensity of postsurgical pain among patients, and whether their preoperative psychological make-up might be an attributable factor for these marked variations.

As it is well known, the experience of pain is a complex phenomenon [2]. Initially there is nociception, which is the 'physiological' component of pain and then there is the experiential patient suffering, which is the 'emotional subjective' component [2].
In many chronic pain syndromes, the latter may exist even without a considerable nociceptive input; or even when there is some nociceptive input, this may not necessarily correlate with the patient's intense emotional experience of pain; hence the justification for the influence of psychological factors [3]. However, in acute postsurgical pain, when there is a constant barrage of nociceptive input from the surgical site, how much will be the influence of patient's psychological factors in the overall emotional experience of pain?

It is a common observation that in similar groups of patients undergoing the same surgery under identical conditions of anesthesia and analgesia, there are always some patients who constantly complain of severe pain, while others do not. These variations are commonly explained as differences in the so-called 'pain thresholds'. However, these variations in pain between individual patients following identical surgical procedures may suggest that there may be a possible influence of patient psychological factors in the experience of acute pain also.

*Department of Clinical Surgical Sciences, The University of the West Indies, St Augustine, Trinidad \& Tobago; 


\section{“The most important}

clinical aspect of the 'emotional' component of acute pain is that it is quite possible to address this in the preoperative period to alleviate the intense negative emotional experience of postsurgical pain, with

pharmacotherapy as well as psychotherapy."
There is enough evidence from numerous clinical studies that the 'anxiety' status of a patient may be strongly associated with the intensity of the surgical pain experience [4-8]. Most studies have applied scoring systems such as the Hospital Anxiety and Depression Scale to quantify the patient psychological factors [4-8]. Some studies have found that higher the anxiety score in the preoperative period, higher the postoperative pain intensity [9].

When men undergoing radical prostatectomies were assessed using the Hospital Anxiety and Depression Scale and the Multidimensional Health Locus of Control, higher pain scores were found in patients with preoperative depression [10,11]. Even in patients undergoing surgeries with moderate intensity pain such as laparoscopic tubal ligations, their anxiety, mood and psychosocial vulnerability were found to be important preoperative indicators of postoperative pain intensity [12]. In patients undergoing laparoscopic cholecystectomy, preoperative neuroticism influenced their early postoperative pain [13].

In breast cancer patients undergoing radical modified mastectomy, anxiety, depression and unmarried status correlated to both higher postoperative pain as well as dissatisfaction with postoperative analgesia [9,14]. Notably, the patient's 'preoperative expectation' has been found to be an important factor that influences patient satisfaction with postoperative analgesia, which also points to the psychological influence of the overall acute pain experience.

Can there be a neurobiological explanation for the influence of psychological factors in the experience of acute pain? There has been increasing evidence that the proinflammatory cytokines influence both 'pain' as well as the 'mood' of the patient. Proinflammatory cytokines such as IL-6, IL-1 $\beta$, TNF- $\alpha$ are involved with the direct modulation of neuronal activity of both peripheral and CNSs affecting the sensitization to pain. It is well established that these cytokines reduce pain threshold, cause hyperalgesia, sensitize afferent nociceptive neurons and increase the discharges from ' $\mathrm{C}$ ' as well as A-delta fibers [15].

Proinflammatory cytokines also influence hippocampal neurogenesis and hence affect the mood of the patient. Furthermore, they stimulate the hypothalamo-pituitary-adrenocortical axis, activating the monoamine reuptake [16]. Thus it is possible that there may be a complex interaction of the cytokines, with regard to pathophysiology of 'pain' as well as the 'mood' of the patient.

The acute inflammation following surgery is associated with high levels of proinflammatory cytokines, [17] which may not only have an effect in the neuronal activity to cause central and peripheral hypersensitization, but may also interact with all the other areas of the brain affecting the mood of the patient. When there is pre-existing anxiety and depression in patients, this complex interaction between the cytokines and monoamines may cause further reduction in the coping mechanisms of the patients. This may result in an increase in both the 'nociceptive' and the 'emotional' components of pain.

There is urgent need for further prospective clinical research in this area. This may include (but not limited to) appropriate quantification of the preoperative psychological status, addressing the disorders aggressively in the preoperative period and elucidating the difference in the experience of acute pain in the postsurgical period. It is also possible to determine the difference regarding the incidence of persistent chronic postsurgical pain by undertaking controlled trials. However, the caveat remains that given the complex nature of pain experience and the difficulties associated with the so-called 'algesimetry', clinical studies have not been consistently able to establish the benefits of many interventions, for example, 'pre-emptive' as well as 'preventive' analgesia. There are avenues in basic sciences research involving pro- and anti-inflammatory cytokines, antagonists and their clinical benefits. In addition, basic sciences research may also be undertaken to determine the relationship between cytokines and monoamines.

The most important clinical aspect of the 'emotional' component of acute pain is that it is quite possible to address this in the preoperative period to alleviate the intense negative emotional experience of postsurgical pain, with pharmacotherapy as well as psychotherapy [18].

Currently, most often, only physiological disorders and comorbidities are aggressively managed in the preoperative period. However, it is possible, as well as desirable, to proactively manage the preoperative psychological abnormalities, as a part of the preparation of a surgical patient. This may not only be beneficial in the short-term postsurgical pain relief, but also in the long-term, preventing persistent postsurgical pain syndromes as well as other chronic pain syndromes. 
Financial \& competing interests disclosure The author has no relevant affiliations or financial involvement with any organization or entity with a financial interest in or financial conflict with the subject matter or materials discussed in the manuscript. This includes employment, consultancies, honoraria, stock ownership or options, expert testimony, grants or patents received or pending, or royalties.

No writing assistance was utilized in the production of this manuscript.

\section{References}

Papers of special note have been highlighted as: - of interest; $\bullet$ of considerable interest

1 Adams LM, Turk DC. Psychosocial factors and central sensitivity syndromes. Curr. Rheumatol. Rev. 11, 96-108 (2015).

2 Part III: pain terms, a current list with definitions and notes on usage. In: Classification of Chronic Pain (Second Edition). Merskey H, Bogduk N (Eds). IASP Task Force on Taxonomy, IASP Press, WA, USA, 209-214 (1994).

-• Definitions of pain syndromes.

3 Tavel ME. Somatic symptom disorders without known physical causes: one disease with many names? Am. J. Med. 128(10), 1054-1058 (2015).

- Pain syndromes without physical causes explained.

4 Bjelland I, Dahl AA, Haug TT, Neckelmann D. The validity of the Hospital Anxiety and Depression Scale. An updated literature review. J. Psychosom. Rev. 52, 69-77 (2002).

5 Montorezi A, Vahdaninia M, Ebrahimi M, Jarvandi S. The Hospital Anxiety and Depression Scale (HADS): translation and validation study of the Iranian version. Health Qual. Life Outcomes 1, 14 (2003).

6 Herrero MJ, Blanch J, Peri JM, De Pablo J, Pintor L, Bulbena A. A validation study of Hospital Anxiety and Depression Scale (HADS) in a Spanish population. Gen. Hosp. Psychiatry 25, 277-283 (2003).
7 Marcolino JAM, Mathias LAST, Piccinini Filho L, Guarantini AA, Suzuki FM, Alli LAC. Hospital Anxiety and Depression Scale: a study on the validation of the criteria and reliability on pre-operative patients. Rev. Bras. Anestesiol. 57, 52-62 (2007).

8 Michopoulos I, Douzenis A, Kalkavoura C et al. Hospital Anxiety and Depression Scale (HADS): validation in a Greek general hospital sample. Ann. Gen. Psychiatry 7, 4 (2008).

9 Özalp G, Sarioglu R, Tuncel G, Aslan K, Kadiogullari N. Pre-operative emotional states in patients with breast cancer and postoperative pain. Acta Anaesthesiol. Scand. 47(1), 26-29 (2003).

- Good evidence for preoperative psychological status related to postoperative pain.

10 Wickström Ene K, Nordberg G, Sjöström B, Bergh I. Prediction of postoperative pain after radical prostatectomy. BMC Nursing 7, 14 (2008).

11 Wickström K, Nordberg G, Gaston Johansson F. Predictors and barriers to adequate treatment of postoperative pain after radical prostatectomy. Acute Pain 7, 167-176 (2005).

12 Rudin A, Wölner-Hanssen P, Hellbom M, Werner MU. Prediction of post-operative pain after a laparoscopic bilateral tubal ligation procedure. Acta Anaesthesiol. Scand. 52, 938-945 (2008).
13 Bisgaard T, Klarslov B, Rosenburg J, Kehlet $\mathrm{H}$. Characteristics and prediction of early pain after laparoscopic cholecystectomy. Pain 90, 261-269 (2001)

14 Katz J, Poleshuck EL, Andrus CH et al. Risk factors for acute pain and its persistence following breast cancer surgery. Pain 119(1), 16-25 (2005).

15 Ozaktay AC, Kallakuri S, Takebayashi T et al. Effects of interleukin-1 beta, interleukin- 6 and tumor necrosis factor on sensitivity of dorsal root ganglion and peripheral receptive fields in rats. Eur. Spine J. 15, 1529-1537 (2006)

16 Rosenblat JD, Cha DS, Mansur RB, McIntyre RS. Inflamed moods: a review of the interactions between inflammation and mood disorders. Prog. Neuropsychopharmacol. Biol. Psychiatry 53, 23-34 (2014).

17 Franke A, Lante W, Fackeldey V et al. Pro-inflammatory cytokines after different kinds of cardio-thoracic surgical procedures: is what we see what we know? Eur. J. Cardiothorac. Surg. 28(4), 569-575 (2005).

18 Bradshaw P, Hariharan S, Chen D. Does preoperative psychological status of the patient affect post-operative pain? - a prospective study from the Caribbean. Brit. J Pain doi:10.1177/2049463716635680 (2016) (Epub ahead of print).

- Recent paper with statistical evidence for psychological factors and acute surgical pain. 